\title{
Giuli Shabashvili
}

Ketevan Gochitashvili

Tbilisi State University, Georgia

\section{The Role of Tutor's Feedback in Writing E-Course}

\begin{abstract}
Paper aims to discuss the type, role and features of feedback of online writing course within the Georgian higher educational environment. Regulations of E-Learning Education is not set yet in the country. Therefore tutors are not experienced to run ecourses in general and the role/ importance of e-feedback is almost unfamiliar to them. The paper is preliminary research which aims to reveal the tutors' attitudes/ readiness to apply e-feedback in their further activities.

The research was conducted by following methods:

Interviews: teachers were asked what do they think about importance of e-feedback and to which extent are they experienced in this regard.

Questioners: teachers were given information about the main writing activities (Content, Structure, Analyse, Sources, Citation...) and main type of Feedback (Negative, Positive, Group, Corrective, Preventive, Peer, Evaluative) for each activity. Questioners contain the list of different feedback tools (e-mail, Forum, Private message, Audio/video-feedback...) as well. Teachers were given the opportunity to choose the most appropriate combination of feedback tools and types of each writing activities.

Data analyse and results: The research reveals that instructors would prefer FtoF communication and traditional evaluation. As for the above mentioned combinations given in questionnaires, they were choosing simplest and not specific variations. Thus, they are less aware of the type of feedbacks and did not realize the possibilities and effectiveness. The paper studies the main reasons of it and based on both theoretical approaches and analysed data gives the recommendations to tutors. The results are generalized and prepared as a guidelines for the course designers and authors.
\end{abstract}

Keywords: E-learning, Feedback types, Writing Course, Learning, Writing Tutors, Education. JEL classification: Health, Education, and Welfare

\section{Introduction}

The technology and methods tutors apply upon e-courses differ from the methods of face-to-face training. Despite the fact that the outlined goals are identical in contextual terms, approaches and activity format constantly requires implementation of significant changes and updates from the tutors subsequently 
following development of the technologies and academic platforms.

Various scientific works provide the indications to the challenges the electronic course tutors encounter, including one of the grave challenges - instant response to the students and correct formulation of feedback (William, 2002).

Feedback is one of the commonly applied types of intervention by the tutors, the objective of which in widely spread terms, is: feedback gives students clear, purposful, specific instructions how to improve and develop their writing skills

Feedback, in e-course, along with its initial function, assumes the additional task - to fill the gap of relations on personal level between the student and tutor. As we can conclude on the basis of practice, ecourses are characterized with sundry shortcomings, which are less revealed in direct training process, for instance, scarcity of the personal contact, asynchronicity, minimal opportunity of instant question and answer mode; restriction of instant response opportunity etc.

We might state that the feedback allows filing the significant part of these gaps, as with feedback, the tutor is capable, through various channels and technology, to improve the shortcomings entailed with lack of direct communication and to provide the student with due directives.

Besides, Teachers 'transmit' feedback messages to students about what is right or wrong in their academic work, about its strengths and weaknesses, and students use this information to make subsequent improvements (Murtagh, Baker, 2009). However, development of feedback was always accompanied with the risk of demotivation of the student as the students are often dissatisfied with the feedback they receive, in terms of lack of specificity with regard to how to improve; it being difficult to understand; and, it may have potentially negative effects on students' selfconfidence and motivation (Murtagh, Baker, 2009). This risk even further increases when the teacher is oriented to application of the direct and negative feedback solely.

It is also noteworthy that there are universal standards on the one hand upon creation of feedback, application of which is possible for any academic e-course, and on the other hand, deriving from the content area, we have to take various specifications into account

Constant guidance of the teacher in the teaching/learning process of the e-course for writing is vital for the student for:

- Acknowledgment of strengths and weaknesses; 
- Acknowledgement of solution ways for weaknesses;

- Mastering the strategies which will facilitate $\mathrm{him} / \mathrm{her}$ to create the writing on the one hand and improve the created writing on the other hand, as he/she has no direct communication with the teacher.

Feedback is one of the most effective means for the student to become the selfregulated learner. It allows maximal reflection and covering the needs of the student and facilitating to improvement of his/her weaknesses.

\section{Objective of the Study}

The study aims at estimation of the role of feedback for the e-course on writing in native language on the basis of the examples available in the Georgian higher educational sphere. The work is of the preliminary study nature and aims at reflection of the obtained outcomes to the e-course currently under processing and activity of the tutor's training.

Currently, e-training is not provided with the legislative support on state level in Georgia and hence, the number of such courses is quite restricted. As to the ongoing courses, most of them are attributed to blended learning instead of the pure e-learning. Due to the hereof circumstances, study of commitment and motivation of the teachers of the writing course has become the subject of our survey. E-courses in the higher educational sphere of Georgia are established at relatively passive extent. Upon formation of hereof courses, it was paramount for us to study commitment, attitude, mood and capacities of the teachers they would apply in conduct of the hereof course. Hence, as a result of cooperation with the teachers of sundry Universities, we have conducted the preliminary survey aiming at collection of information to serve the basis for development of the guidelines - teaching instructions on the one hand and for reflection thereof in the context, form and strategies of the e-courses. We have questioned 41 teachers altogether.

\section{The limitations of the study:}

Since the low of distance learning is not adopted yet distance and online learning is not widely practiced in Georgia thus lack of variety of sources is vivid and restricted experience of instructors is mentionable. Moreover lack of tutors' readiness to cooperate plays a hindering role in this regard as well.

\section{Analysis of the survey outcomes}

The first part of the questionnaire was of the general nature and was purposed to verify the level of knowledge and awareness of the teachers about e-teaching in general and more precisely, necessity and role of the feedback. 
Feedback-related questions

\begin{tabular}{|l|l|l|l|}
\hline & $\begin{array}{l}\text { Less } \\
\text { important }\end{array}$ & Averagely important & Important \\
\hline $\begin{array}{l}\text { How can you estimate } \\
\text { importance of the feedback } \\
\text { of e-course and why? }\end{array}$ & & & \\
\hline
\end{tabular}

\begin{tabular}{|l|l|}
\hline $\begin{array}{l}\text { How frequently the teacher shall } \\
\text { apply feedback? }\end{array}$ & $\begin{array}{l}\text { T frequently, upon accomplishment of every new topic, } \\
\text { rarely, never, your option. }\end{array}$ \\
\hline $\begin{array}{l}\text { What is the difference between } \\
\text { estimation and e-feedback? }\end{array}$ & \\
\hline $\begin{array}{l}\text { What is the difference between } \\
\text { correction and e-feedback? }\end{array}$ & \\
\hline $\begin{array}{l}\text { What shall be taken into account } \\
\text { upon conclusion of the e-feedback } \\
\text { of the written work? }\end{array}$ & \\
\hline $\begin{array}{l}\text { What are the impediments for the } \\
\text { teacher in conclusion of the } \\
\text { comprehensive e-feedback? }\end{array}$ & \\
\hline $\begin{array}{l}\text { Which type of feedback is } \\
\text { recognized as effective upon } \\
\text { estimation of the written works } \\
\text { and why? }\end{array}$ & $\begin{array}{l}\text { Positive, negative, direct, indirect, group, individual, } \\
\text { prelimary, preventive, your option. }\end{array}$ \\
\hline $\begin{array}{l}\text { Are you ready to apply the } \\
\text { comprehensive feedback upon } \\
\text { conduct of the e-course for }\end{array}$ & \\
\hline
\end{tabular}

The survey revealed that the situation is dissimilar and the answers depend on the University and the students, as well as the age of the teachers, motivation and even on personal qualities. However, we still have the general picture. Namely, the attitude of 
the teachers towards the e-feedback in general is neutral. Just a few teachers expressed negative attitude to necessity of conclusion of the comprehensive explanatory feedback. As to commitment, the part of the teachers according to selfassessment, is not ready either in technical or in contextual terms (20\%), while the part of the teachers is ready to meet the hereof challenge after certain retraining works (53\%) and the remaining part expresses commitment to be involved in similar activity $(27 \%)$.

Question: How can you estimate importance of the feedback of e-course and why? The teachers presume that importance of feedback is not conclusive and they provide own practice, practice of their colleagues as an argument, when they succeed in fulfillment of the direct teaching task without feedback. Most of the teachers consider that the role of feedback is averagely important (25), less important (10) and very important (6).

How frequently the teachers shall apply feedback? In this event, the answers were dissimilar again, which makes formation of clear picture and regularity impossible. The optional answer - your option - actually failed. The teachers mainly relied on the offered answers. It is noteworthy that none of them marked the answer - never, though it does not ensure making certain conclusions as the teachers considered it as a negative answer and that is why the likely abstained from marking it.

Question: What is the difference between estimation and e-feedback? Nine teachers left this cell unmarked and the answers of the others can be grouped as follows: most of them see no difference (18). Some of them state that these two systems partially coincide, though the their answers are not substantiated or extended (10), and all the remaining (3) state that estimation of a particular task is a complete process and feedback is the extended work which shall not be limited with single activity and serves as a significant facilitation to progress of a pupil.

Question: What is the difference between correction and e-feedback? This question appeared to be clearer for the respondents. Correction is a more commonly applied technology in their pedagogical practice, so they managed to be precise in defining that correction implies detection of mistakes and indication thereto, while feedback is a far more comprehensive and multidimensional technology, though we obtained the ness number of specified answers regarding feedback.

What shall be taken into account upon conclusion of the e-feedback of the written work? It is noteworthy that the teachers 
relied on their previous pedagogical practice and emphasized the product created by the pupil and mostly spoke about what shall be estimated. There were only two teachers emphasizing the structure and characteristics of feedback.

The answers of the teachers can be classified into sundry groups: lingual mistakes and style (5 teachers), context of the work (8 teachers), substantiated and consecutive discussion (10 teachers), citing and paraphrase (4 teachers), feedback organization and structure (2 teachers). Eight teachers gave combined answers, for instance: according to them, emphasis shall be made as on the lingual aspect, so the context of the work or substantiated and consecutive discussion.

What are the impediments for the teacher in conclusion of the comprehensive e-feedback? Answering this question appeared easiest for the teachers. Following were the most significant impediments for implementation of this activity: 1 . Technical impediments (4); 2. Lack of experience (9); 3. Time deficit (12); 4. Lack of enthusiasm of the pupils and passive attitude thereby (7); 5. Lack of motivation - not reflected in the curriculum and cannot be recognized as necessary (9).

Which type of feedback is recognized as effective upon estimation of the written works and why? The answers to this question were diverse inasmuch as the closed-type question comprised sundry different options offered. It is noteworthy that only three lecturers substantiated their answers, while others merely marked the desired option. They left the cell -your option - unmarked as the teachers abstained from filling it. The answers were as follows: positive (6), negative (14), group (3), individual (9), preliminary preventive (5), your option. Some of the teachers marked several answers simultaneously.

The fourth component of the survey comprised the in-depth interview with the teachers. Fourteen teachers have been questioned. The interview consisted of several questions, namely: 1. How often feedback is applied upon conduct of the ecourse, 2. Do you prefer direct or indirect for of feedback, 3. What are the challenges the teachers might encounter upon feedback.

1. Most of the teachers gave the answer to the first question that application of feedback upon any academic activity is not necessary, and they prefer correction and estimation;

2. As to the direct and indirect forms of feedback, most of the teachers prefer direct feedback as they consider that the information 
provided through the direct message will be more productive and rapid.

3. As to the third question, outcomes of the interview even further enhanced the answers of the questionnaires. Besides, we found out that the teachers prefer the direct format of communication with the students and in some cases, they consider some platforms (for instance, blogs, facebook, forums) as unjustified for e-feedback as these are the formats less serious, less result-oriented, entertaining and non-educational. Besides, the teachers presume that time to be spent on feedback, shall be preferably consumed on obtainment of new information, planning of the course and establishment of new strategies.

The third component of the survey implies the approach of the teachers to preliminary definition of possible combinations of due means and types of feedback for writing components.

We individually offered them the list of the feedback means: Written text via email:Pdf documents, Word documents; Information on Forum Private message, Audio/video-feedback, Comments, Online discussion, Blogs, Video conference and discussion, Sharing best practices on different platforms or media, Prepared databases

Feedback types: Negative feedback, Positive feedback, Group feedback, Corrective feedback, Preventive feedback, Peer feedback, Evaluative feedback

And types of the writing components: Content, Structure, Argument, Analyze, Coherence, Sources, Citation, Language and grammar, Genres, Tone, punctuation.

The teachers were free to choose and define respective type and mean of feedback for each writing component.

Hereby, we provide the model of the table to be filled in:

\begin{tabular}{|l|l|l|}
\hline Writing component & \multicolumn{1}{|c|}{ Feedback means } & \multicolumn{1}{c|}{ Feedback types } \\
\hline Content & $\bullet$ Written text via e-mail:Pdf & Negative feedback, \\
& documents, Word & Positive feedback, \\
& documents; & Group feedback, \\
& $\bullet$ Information on Forum & Corrective feedback, \\
& $\bullet$ Private message & Preventive reedback, \\
& $\bullet$ Audio/video-feedback & Peer feedback, \\
& $\bullet$ Comments & Evaluative feedback \\
& $\bullet$ Online discussion & \\
& $\bullet$ Blogs & \\
\hline
\end{tabular}




\begin{tabular}{|l|l|l|}
\hline & $\bullet$ Video conference and & \\
discussion & $\bullet$ Sharing best practices & \\
$\bullet$ Prepared databases & \\
$\bullet$ Social Media & \\
\hline
\end{tabular}

Due to similarity of the outcomes and taking the specification of the preliminary study, we considered it expedient to outline the main trends and to evade analysis through the statistical method. Namely, the overwhelming majority of the teachers 98\% prefers the following feedback means for all options offered for writing elements: Written text via e-mail: pdf documents; Word documents; Private messages; Comments; and the following were mostly applied as feedback types: Negative feedback, Corrective feedback, Evaluative feedback.

It is noteworthy that the teachers consider some of the feedback types as acceptable, for instance: group feedback, positive feedback. However, it was outlined that none of the teachers apply peer feedback. As to the e-feedback means, the teachers expressed the negative attitude to some of them, for instance to the instruments such are: Audio/videofeedback, Social Media, Online discussion, Blogs, Video conference and discussion, Sharing best practices and Prepared databases is completely neglected. It allows us stating that the teacher rely on the preliminary skills and transfer the direct teaching experience to the direct e-format, which contradicts with the e-course nature and main principles and makes the resulting process less effective.

\section{Conclusion:}

The survey revealed that:

1. The preliminary survey revealed that the teachers need to obtain some guidelines and instructions to first of all realize application of the writing tasks and e-feedback types and means;

2. Technical maintenance shall be provided to obtain the desired outcome;

3. Institutional support shall be enhanced and the respective requirements shall be reflected to the curriculum;

4. It will have impact on increase of motivation of the teachers;

5. Due to lack of institutional support in Georgian educational sphere, commitment of the teachers and the 
professional level fail to meet the established standards and requirements;

6. Despite the fact that development of the questionnaires revealed relatively similar combinations of inter-relation of the writing components and feedback, we still can state that the teachers acknowledge necessity and importance of feedback at some extent;

7. Feedback and importance thereof, the role of which is particularly important in teaching writing, shall be well acknowledged by the teachers as feedback other than providing various estimation forms, also provides the pupil with the prepared forms, lingual means, structure sand models applicable in the writing process and to facilitate to development of the writing skills of the pupil. Hence, we can mention so-called "double function" of feedback.

\section{Further prospectives:}

Paper is a preliminary research which aims to prepare the guidance for instructors in order to support applying electronic feedbacks within the practical teaching activities.

\section{References}

Lisa Murtagh and Nadine Bake (2009), "Feedback to Feed Forward: student response to tutors' written comments on assignments", Practitioner Research in Higher Education Copyright (C) 2009 University of Cumbria Vol. 3 (1): page 20-28

Massy, William. (2002) “Distance Education: Guidelines for Good Practice.” AFT, May 2002. 